\title{
Consumption of Whole Grains by a Sample of Saudi Adults
}

\author{
Jozaa Zaidan Al Tamimi \\ Department of Nutrition and Food Science, College of Home Economics, Princess Nourah Bint Abdulrahman University, Riyadh, Saudi \\ Arabia
}

\section{Email address:}

jzaltamimi@pnu.edu.sa

\section{To cite this article:}

Jozaa Zaidan Al Tamimi. Consumption of Whole Grains by a Sample of Saudi Adults. International Journal of Nutrition and Food Sciences. Vol. 5, No. 2, 2016, pp. 117-123. doi: 10.11648/j.ijnfs.20160502.14

Received: February 23, 2016; Accepted: March 5, 2016; Published: March 16, 2016

\begin{abstract}
This study aimed to assess the consumption of grain groups and their products in a sample of adult Saudis in Riyadh and to determine how much of whole grains and their products were consumed. The study adopted a descriptive method in which a questionnaire designed to include demographic data, a semi-quantitative dietary frequency form and questions regarding the reasons for not consuming whole grains and their products was administered to the participants. Data were collected from 150 adult Saudis of both sexes. The findings revealed that $43.30 \%$ of the participants consumed whole grains and their products at a rate of 6-11 portions per day, while $57.30 \%$ of the participants did not daily consume any kind of whole grain or their products. Bread and white rice were most often consumed by the participants. Among the participants, $36 \%$ reported that not accepting the taste of whole grains and their products was one of the most important reasons for not consuming them. Other reasons, such as their unavailability in various forms on a daily basis in small food supply stores, were mentioned by $31 \%$ of the participants. The study also revealed the existence of a significant negative correlation between the participants' demographic characteristics and the consumption rate of the group of grains and their products. Higher education level and the family being joint (extended) were correlated with lower consumption of grains group and their products.
\end{abstract}

Keywords: Grains Group, Whole Grains, Adult Saudis, Demographic Data

\section{Introduction}

There is no standardized definition of whole grains; however, there is a pragmatic definition given by the working group of the American Association of Cereal Chemists International (AACI) stating, "whole grains shall consist of the intact, ground, cracked or flaked caryopsis, whose principal anatomical components, the starchy endosperm, germ and bran, are present in the same relative proportions as they exist in the intact caryopsis'. The importance of a specific and precise definition for whole grains stems from the fact that it helps consumers carry out specific dietary recommendations for whole grains, thereby improving their health [1].

Whole grains are a rich source of vitamins, minerals and dietary fibre, with the most important being inulin, $\beta$-glucan and lignans and effective compounds such as phytochemicals, phytosterol, phytin and sphingolipids. Most of these are concentrated in the bran and germ [2]. The contents of these nutrients decrease when whole grains are treated. For example, white refined wheat contains only $7 \%$ of vitamin E, $13 \%$ of pyridoxine and $16 \%$ of magnesium present in whole grain flour. The levels of riboflavin, niacin, zinc, dietary fibre, potassium, thiamine, iron, copper, selenium and folic acid also decrease; however, when wheat flour is fortified, the levels of riboflavin, thiamine, niacin, iron and folic acid are doubled [3].

Many studies have confirmed the health benefits of whole grains and their ability to reduce the incidence of many chronic diseases. Chan et al. [4] found that consuming larger amounts of whole grains and smaller amounts of treated, refined and sweetened grains lowers the risk of pancreatic cancer. Costabile et al. [5] found that consuming whole grains increases the levels of pseudobacteria and lactobacillus in the digestive system and increases the concentration of ferulic acid by 2.5 times, which decreases oxidative damage in the body. Thus, whole grains play a role in protecting our bodies from cardiovascular diseases. Moreover, there is an inverse correlation between consuming large amounts of whole grains and the potential for developing type-two diabetes mellitus [6]. 
Good et al. [7] found that the body mass index and waist circumference of women who consume whole grains are lower than those of their counterparts who do not consume whole grains. Individuals, who consume higher amounts of whole grains, have lower levels of homocysteine, total cholesterol and LDLs in the blood and higher levels of HDLs [8].

In a study of patients with metabolic syndrome, Katcher et al. [9] found that patients who consumed whole grains experienced weight loss. They also had lower weights, waist circumferences and body fat percentages. Furthermore, their stomach fat percentages decreased and their C-reactive protein levels decreased by approximately $38 \%$.

Because of the significant health benefits and dietary value of whole grains, most countries worldwide recommend the consumption of whole grains. Foremost among these countries are Australia, Canada, Chile, China, Colombia, Denmark, France, Germany, Greece, Iceland, India, Latvia, Mexico, the Sultanate of Oman, Singapore, Switzerland, the United Kingdom and the USA. However, there are slight differences in the dietary guidelines and recommendations among these countries. For example, Canada recommends the consumption of 3-8 portions of whole grain a day, depending on the person's sex and age and that the share of whole grains should at least be half of their grain intake. In Mexico, the recommendations require consuming whole grain cereals without sugar and necessitate the consumption of whole grains and legume seeds with every meal. The Sultanate of Oman recommends that an individual with an average daily energy consumption of 2000 calories should daily consume 2-3 portions of whole grains [1].

The USA recommends that an adult who needs 2000 calories a day consume six portions from the grains group, of which whole grains constitute half [10]. In the Kingdom of Saudi Arabia, the Ministry of Health issued the Health Food Palm (dietary guidelines for Saudis) where it stated the importance of selecting whole grains and their products and the importance of keeping away from treated grains and their products to which salt, fats and sugar are added [11]. The World Health Organization in collaboration with the Food and Agricultural Organization of the United Nations pointed out the importance of consuming whole grains on a daily basis for protection from nutrition-related chronic diseases such as cardiovascular diseases and type 2 diabetes mellitus [1].

Despite substantial efforts to increase the consumption of whole grains and include them in daily meals, their consumption remains low. Studies have pointed out that $<1 \%$ of the United States population consumes whole grains as set forth in the dietary guidelines and that $20 \%$ of the population does not consume any kind of whole grain in any form. According to United States Department of Agriculture statistics, Americans prefer treated grains over whole grains by a ratio of 5: 1 . In the United Kingdom, the daily intake of whole grains averaged at approximately $14-16 \mathrm{~g}$, with a third of the adult United Kingdom population not consuming whole grains, in France, the average consumption of whole grains reached $7.3 \mathrm{~g} /$ day [1]. Although there has been a slight increase in the consumption of whole grains over time, their consumption remains low [12]. Hence, this study aimed to assess the consumption of the group of whole grains and their products in a sample of adult Saudis in Riyadh and to determine how much of this consumption included whole grains and their products.

\section{Research Methods}

\subsection{Methodology, Study Population and Sample}

The study adopted a descriptive method. The study population comprised 150 adult Saudis of both sexes (30Males, 120 Females) who were residents of Riyadh. Their ages ranged from 19 to 50 years. Data were collected through 2012-2013.

\subsection{Research Tools}

The key tool in this study was a questionnaire that was specifically designed for the study and that included three main items. The first was designed to record demographic data, including sex, marital status, monthly income, educational level and type of family. The second was a semi-quantitative dietary frequency questionnaire for the group of refined and whole grains and their products, codified as common grain consumption, (such as wheat, barley, corn, rice, millet and rye) and all products and their consumption frequency (daily, weekly, monthly and yearly). The third item was a questionnaire assessing the reasons for not consuming whole grains.

\subsection{Data Collection}

Data were collected through interviews. The portions of refined and whole grains consumed along with the collection varieties of whole grains repeatedly consumed were determined from the quantities assessed and recorded in the semi-quantitative dietary frequency questionnaire.

\subsection{Data Analysis}

Data were summarized. The Statistical Package for Social Sciences (SPSS Inc., Chicago, IL, USA) ver.17 was used for performing the necessary statistical analyses, such as frequencies, percentages, arithmetic means, standard deviation and correlation analysis.

\section{Findings and Discussion}

Table 1 shows the demographic data of the study participants. Of the 150 participants, $80 \%$ were female and $20 \%$ were male. More than half of the participants $(56.00 \%)$ were unmarried. Those with high monthly incomes constituted the majority of the study participants, with the percentage of those having monthly incomes above 10,000 Saudi riyals being $54.00 \%$. Most of the participants had university degrees $(63.30 \%)$, and $85.30 \%$ of the participants belonged to independent families.

Table 2 shows the average number portions of grains group and their products consumed daily and the proportion 
of these portions that comprised whole grains. We notice that $46.00 \%$ of the participants consumed $<6$ daily portions of the grains group and $47.30 \%$ consumed $6-11$ portions daily. Those consuming $>11$ portions daily of all forms of grains were a small percentage, i.e., up to $6.70 \%$. Regarding the share of whole grains in the daily intake of grains, $57.30 \%$ of the participants did not consume any kind of whole grain daily, while $25.30 \%$ consumed less than half the daily intake of grains in the form of whole grains, $11.30 \%$ consumed half of their daily grains group intake in the form of whole grains and only $6.10 \%$ consumed more than half of their daily intake of grains in the form of whole grains. The findings were similar to those of many previous studies. Cleveland et al. [13] reported that adult Americans consume approximately 6-7 daily portions of grains, with only one of these portions comprising whole grains; $36 \%$ consume fewer than one portion a day of whole grains and only $8 \%$ consume no fewer than three daily portions of whole grains. In Britain, it was found that $27 \%$ of children and $30 \%$ of adults do not consume any kind of whole grain at all $[14,15]$. A study conducted on 598 students who were aged 8-13 years in the Netherlands revealed that the average daily consumption of whole grains and their products amounted to $45 \mathrm{~g}$. Sharma et al. [16] pointed out that $55.6 \%$ of the participants consumed refined grains and that $30.8 \%$ consumed whole grains. Abuzai [17] found that $45.3 \%$ of secondary stage students in rural areas of the Kingdom of Saudi Arabia consumed seven portions or more of the grains group daily compared with secondary school students in urban areas where the percentage of students consuming seven portions or more reached $48.3 \%$. These data demonstrate that daily consumption of grains and their products is greater in urban areas. The nutritional balancing book in the Kingdom of Saudi Arabia reported that the individual annual average percentage of grains group and their products in the diet is increasing in the Kingdom of Saudi Arabia. It was 136.1 $\mathrm{kg} / \mathrm{year}$ on an annual average for the period of 1996-1998 and reached $144.3 \mathrm{~kg} /$ year on an annual average for the period 2002-2004, which is an annual increase of 8.2 $\mathrm{kg} /$ year. That is the equivalent of $6 \%$ of the Saudi nutritional balance, confirming that the individual's daily share of calories amounted to 3015.5 calories on an annual average during the period 2002-2004. The grains group and their products rank first in the individuals share of calories, constituting $47.3 \%$ [18].

Table 1. Descriptive Data of Study Participants*

\begin{tabular}{|c|c|c|c|}
\hline Descriptive Data & Categories & Frequency & Percentage \\
\hline \multirow{2}{*}{ Sex } & Male & 30 & 20.00 \\
\hline & Female & 120 & 80.00 \\
\hline \multirow[t]{2}{*}{ Total } & & 150 & 100 \\
\hline & Unmarried & 84 & 56.00 \\
\hline \multirow[t]{2}{*}{ Marital Status } & Married & 62 & 41.30 \\
\hline & Divorced / widowed & 4 & 2.70 \\
\hline \multirow[t]{2}{*}{ Total } & & 150 & 100 \\
\hline & Less than $4,000 \mathrm{SR}$ & 6 & 4.00 \\
\hline \multirow{3}{*}{ Monthly Income } & $4,000-7000 \mathrm{SR}$ & 28 & 18.70 \\
\hline & $7,001-10,000 \mathrm{SR}$ & 35 & 23.30 \\
\hline & Above $10,000 \mathrm{SR}$ & 81 & 54.00 \\
\hline \multirow[t]{3}{*}{ Total } & & 150 & 100 \\
\hline & Elementary Stage & 1 & 0.70 \\
\hline & Intermediate Stage & 14 & 9.30 \\
\hline \multirow{4}{*}{ Educational Level } & Secondary Stage & 19 & 12.70 \\
\hline & Bachelor Degree & 95 & 63.30 \\
\hline & Higher Diploma & 14 & 9.30 \\
\hline & Graduate Studies & 7 & 4.70 \\
\hline Total & & 150 & 100 \\
\hline \multirow{2}{*}{ Family Kind } & Nuclear & 128 & 85.30 \\
\hline & Joint & 22 & 14.70 \\
\hline Total & & 150 & 100 \\
\hline
\end{tabular}

*Number of participants, 150

Table 2. Average number of portions of grains group taken daily by sample participants and share of whole grains in them*.

\begin{tabular}{|c|c|c|c|}
\hline Item & Categories & Frequency & Percentage \\
\hline \multirow{3}{*}{ Daily Grains Consumption } & Less than 6 portions & 69 & 46.00 \\
\hline & From 6 to 11 portions & 71 & 47.30 \\
\hline & More than 11 portions & 10 & 6.70 \\
\hline Total & & 150 & 100 \\
\hline \multirow{3}{*}{ Daily Consumption of Whole Grains } & Not consumed at all & 86 & 57.30 \\
\hline & Less than half the daily intake of grains & 38 & 25.30 \\
\hline & Half of the daily intake of grains & 17 & 11.30 \\
\hline Total & & 150 & 100 \\
\hline
\end{tabular}

*Number of participants, 150 
Figure 1 shows the kinds of grains and their products consumed by the participants in this study. The most frequently consumed kind being treated grains and their products, such as rice, white bread and ready breakfast cereals and the products of white wheat flour such as pastries, macaroni and cakes. Whole grains and their products consumed most by the participants were bread, bran bread, crushed grain bread and bran biscuits.

Figure 2 shows the frequency with which the various kinds of grains are consumed, with bread and white rice being the kinds eaten most on a daily basis. The products of whole grains were consumed only weekly, monthly or even yearly by most of the participants. Al-Qauhiz [19] pointed out that $47.3 \%$ of adult female Saudis consumed rice daily, while $30.4 \%$ consumed white bread daily. In a United States Department of Agriculture report on Saudi Arabia, Hassan and Hussein [20] said that wheat flour is the most important ingredient in Saudi food because it is used in making domestic bread, burger bread and sandwich and other kinds of Western bread, such as the French bread and pizza. A Saudi individual's daily average consumption of flour is approximately $235 \mathrm{~g}$. Barley is used in the Kingdom of Saudi Arabia mostly in animal feed. Likewise, corn is largely used for feeding animals and a small percentage of it is used for producing starch and sugar solutions. Rice is the most commonly used crop by Saudis, with $43 \mathrm{~kg}$ annually consumed by each individual. Sharma et al. [16] said that the products of whole grains consumed most were whole wheat bread and barely, followed by corn, with the exception of men of Hawaiian or Japanese descent, for whom brown and wild rice was the second largest source of whole grains. With respect to treated and refined grains, white rice and white bread are the most consumed.

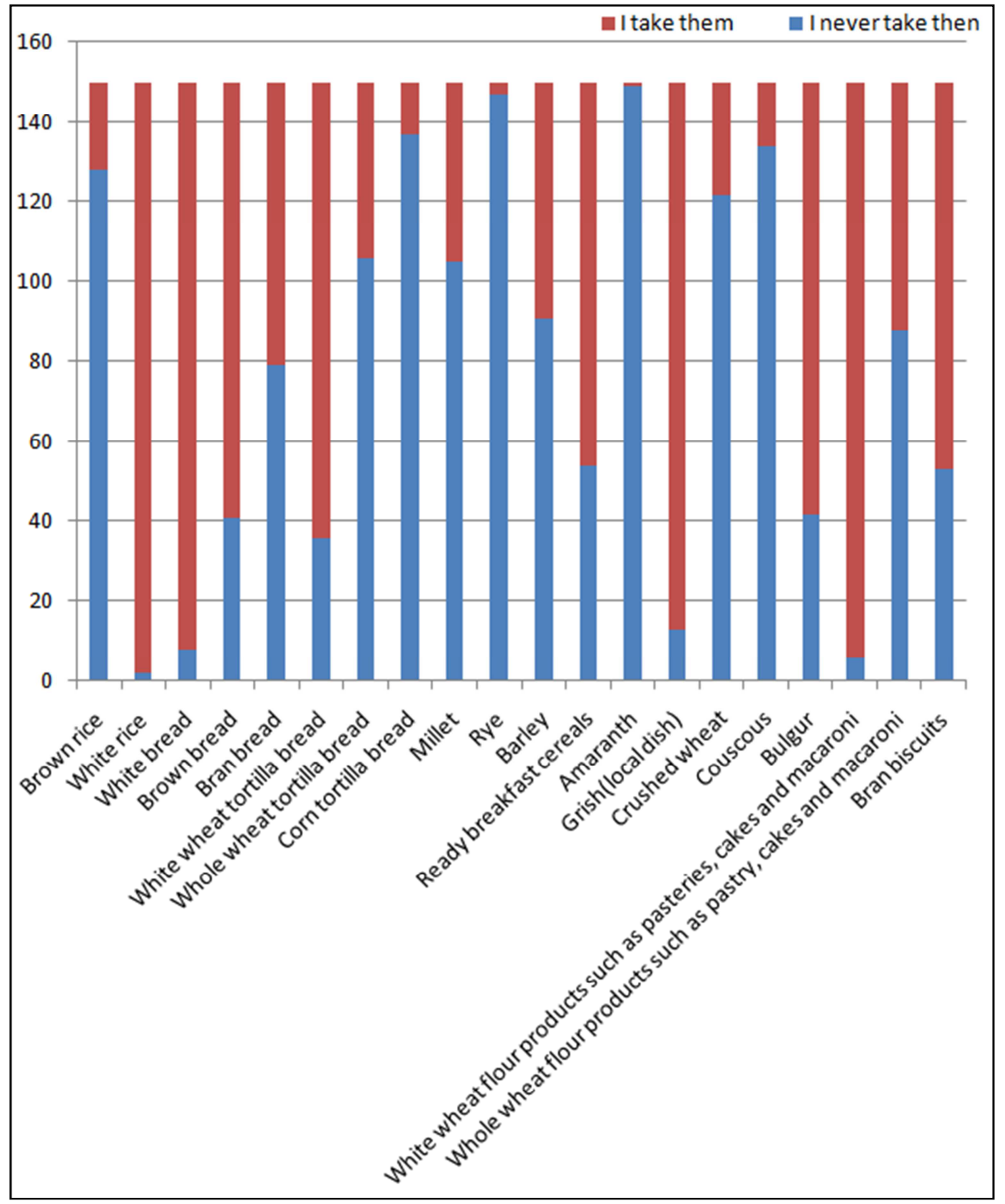

Figure 1. Kinds of grains and their products consumed by the study participants. 


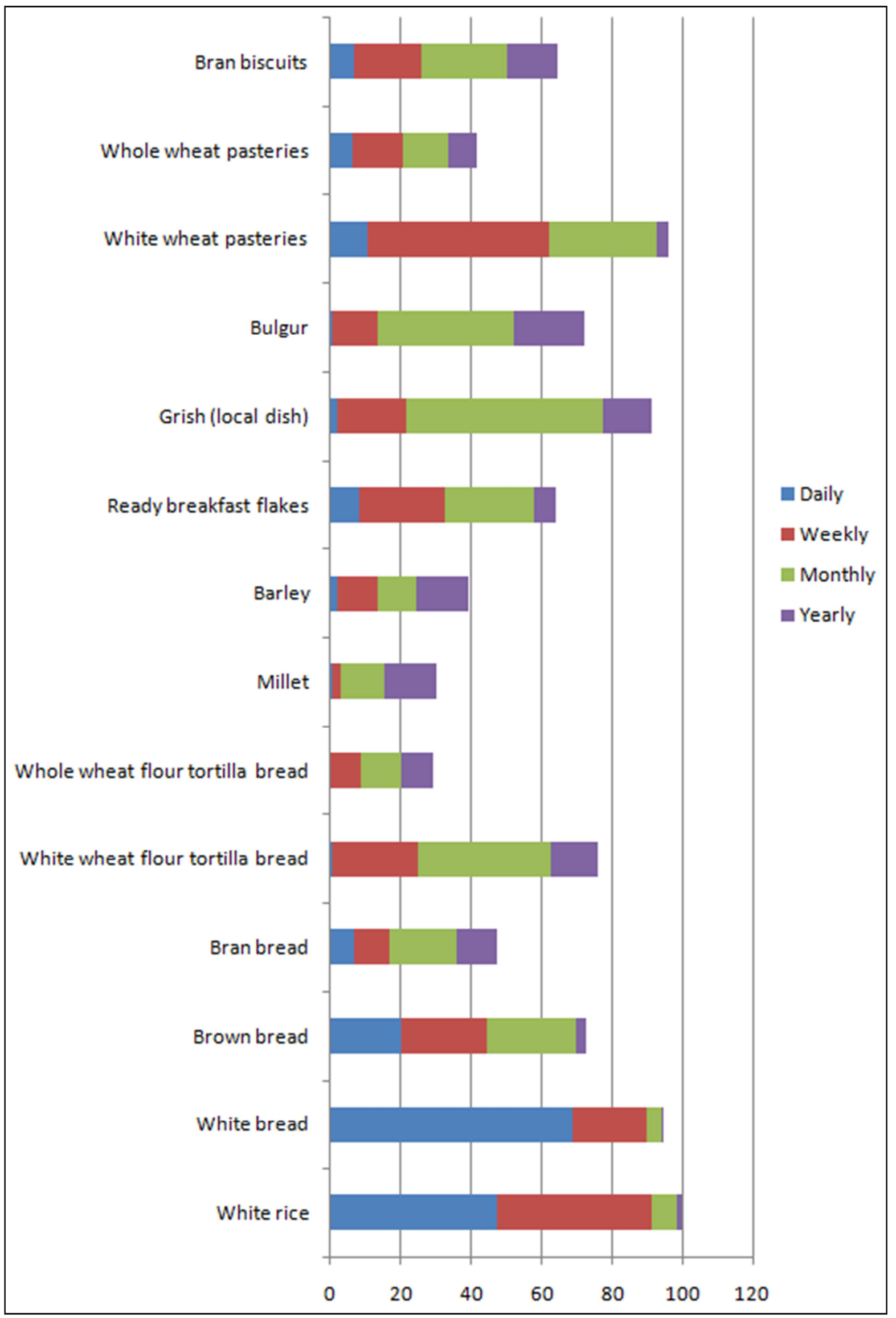

Figure 2. Frequency of consuming common kinds of grains group and their products by study participants. 
Table 3. Reasons for not taking whole grains and their products by study participants*.

\begin{tabular}{l|l|l|l|l|}
\hline Reasons for not taking whole grains & Frequency & Percentage \\
\hline Non acceptance of their taste & 54 & 36.00 \\
For health reasons & 3 & 2.00 \\
Their high price & 1 & 0.70 \\
Did not know about them & 45 & 30.00 \\
Other reasons & 47 & 31.30 \\
Total & 150 & 100 \\
\hline
\end{tabular}

*Number of participants, 150

Table 4. Relationship between study participant demographic data and average daily consumption of grains and whole grains and their products.

\begin{tabular}{|c|c|c|c|c|}
\hline \multirow{2}{*}{ Item } & \multicolumn{2}{|l|}{ Daily average of grains consumption } & \multicolumn{2}{|c|}{ Daily average of whole grains consumption } \\
\hline & Spearman Correlation Coefficient & Statistical Significance & Spearman Correlation Coefficient & Statistical Significance \\
\hline Sex & -0.102 & 0.214 & 0.014 & 0.863 \\
\hline Marital Status & 0.044 & 0.593 & -0.031 & 0.708 \\
\hline Economic Level & 0.006 & 0.939 & 0.120 & 0.143 \\
\hline Educational Level & -0.173 & $* 0.035$ & -0.043 & 0.603 \\
\hline Family Kind & -0.210 & $* 0.010$ & 0.037 & 0.654 \\
\hline
\end{tabular}

*Correlation is significant at the $\mathrm{p}=0.05$ level.

Table 3 shows the reasons for the low daily consumption of whole grains among the study participants. Thirty-six percent of the participants said that the taste of whole grains is not palatable, whereas $31.30 \%$ of the participants gave other reasons. Foremost among these other reasons was that the products of whole grains are unavailable in small supply centres that are close to their homes but are available in large supermarkets, which makes them difficult to get. They also mentioned the different tastes of the family members. Thirty percent of the participants said that they did not know about whole grains or had not heard of their importance or value to health before reading the dietary guidelines pertaining to them. The lowest percentage went to the two reasons of health problems and high price, which counted for $2 \%$ and $0.70 \%$ respectively. These percentages are in agreement with the Health Grain project [21], which stated that the lack of the knowledge about whole grains and their health benefits was among the most important reasons of the low consumption. The Health Grain project also stated that consumers have difficulty in differentiating them from whole grains, find their taste unpalatable and find their price expensive.

Table 4 shows the correlation between the demographic data and daily average consumption of whole or treated grains and their products; we observe a statistically significant negative correlation between the study participants' educational levels and family kind and their average daily consumption of grains and their products. No statistically significant relationship appeared between any of the study participants' demographic data and the average consumption of whole grains and their products. Contrary to what has been reported by Lang \& Jebb [14], sex has an effect on the amount of grains consumed. Men consume more whole grains than women because men eat more food than women. In Britain, the higher the individual's educational level and income, the more whole grains the individual consumes.

In summary, this descriptive study used a specifically designed questionnaire, which was administered during interviews, to assess the consumption of whole grains in 150 Saudi men and women living in Riyadh. The majority $(57.30 \%)$ of the participants did not consume any kind of whole grain or whole grain products daily. The poor taste and difficulty in obtaining whole grains and whole grain products were major reasons for the lack of whole grain consumption. The study concluded that higher education level and joint (extended) family were correlated with a lower consumption of whole grains and their products.

\section{Conclusions}

The consumption of whole grains and their products is important because of their health benefits. However, this study indicates that the daily consumption of whole grains and their products remains low. More than half of the participants did not consume any kind of whole grain product on a daily basis for several reasons. The most important reasons are that the participants did not accept the taste of whole grains and whole grain products. In addition, whole grains and their products are unavailable in small supply places on a daily basis. This study stresses the importance of informing the Saudi society regarding the importance of consuming whole grains and their products and the importance of making them part of the daily diet. To make improvements, it is important to work towards improving the taste of these products, making them acceptable to the consumer and providing them in small supply places in the residential quarters.

\section{References}

[1] M. G. Ferruzzi, S. S Jonnalagadda, S. Liu, L. Marquart, N. McKeown, M. Reicks, G. Riccardi, C. Seal, J. Slavin, F. Thielecke, J. Kamp, and D. Webb, Developing a standard definition of whole-grain food for dietary recommendations: summary report of a multidisciplinary expert roundtable discussion. Adv. Nutr. vol. 5, pp. 164-176, 2014. 
[2] S. S. Jonnalagadda, L. Harnack, R. H. Liu, N. McKeown, C. Seal, S. Liu, and G. C. Fahey, Putting the Whole Grain Puzzle Together: Health Benefits Associated with Whole GrainsSummary of American Society for Nutrition 2010 Satellite Symposium. J. Nutr. vol. 14, pp. 11011-1022, 2010.

[3] Whole grains council. (2006). The Inside story. Nutrition action health letter.

[4] J. M. Chan, F. Wang, and E. A. Holly, Whole grains and risk of pancreatic cancer in a large population-based case-control study in the San Francisco Bay Area, California. Am. J. Epidemiol. vol.166, pp. 1174-1185, 2007.

[5] A. Costabile, A. Klinder, F. Fava, A. Napolitano, V. Fogliano, C. Leonard, G. R. Gibson, and K. M. Tuohy, Whole-grain wheat breakfast cereal has a prebiotic effect on the human gut microbiota: a double-blind, placebo-controlled, crossover study. Br. J. Nutr. vol. 99, pp. 110-120, 2008.

[6] J. S. De Munter, F. B. Hu, D. Spiegelman, M. Franz, and R. M. van Dam, Whole grain, bran, and germ intake and risk of type 2 diabetes: a prospective cohort study and systematic review. PLoS Med. vol. 4, pp. 261, 2007.

[7] C. K. Good, N. Holschuh, A. M. Albertson, and A. L. Eldridge, Whole grain consumption and body mass index in adult women: an analysis of NHANES 1999-2000 and the USDA pyramid servings database. J. Am. Coll. Nutr. vol. 27. pp. 80-87, 2008.

[8] M. K. Jensen, P. Koh-Banerjee, M. Franz, L. Sampson, M. Gronbaek, and E. B. Rimm, Whole grains, bran, and germ in relation to homocysteine and markers of glycemic control, lipids, and inflammation. Am. J. Clin. Nutr. vol. 83, pp. 275283, 2006.

[9] H. I. Katcher, R. S. Legro, A. R. Kunselman, P. J. Gillies, L. M. Demers, D. M. Bagshaw, and P. M. Kris-Etherton, The effects of a whole grain-enriched hypocaloric diet on cardiovascular disease risk factors in men and women with metabolic syndrome. Am. J. Clin. Nutr. vol. 87, pp. 79-90, 2008.

[10] Dietary Guidelines for Americans 2015-2020. (2015). 8th Edition. Available at http://health.gov/dietaryguidelines/2015/guidelines/.
[11] Ministry of Health. (2012). Dietary Guidelines for Saudis The healthy Food Palm General Directorate of Nutrition. http://www.moh.gov.sa/.

[12] J. E. Maras, P. K. Newby, P. J. Bakun, L. Ferrucci, and K. L. Tucker, Whole grain intake: The Baltimore Longitudinal Study of Aging. J. Food Compost. Anal. 1. vol. 22, pp. 53-58, 2009.

[13] L. E. Cleveland, A. J. Moshfegh, A. M. Albertson, and J. D. Goldman, Dietary Intake of Whole Grains. J. Am. Coll. Nutr. vol. 19, pp. 331-338, 2000.

[14] R. Lang, and S. A. Jebb, Who consumes whole grains, and how much? Proceedings of the Nutrition Society. vol. 62, pp. 123-127, 2003.

[15] C. W. Thane, A. R. Jones, A. M. Stephen, C. J. Seal, and S. A. Jebb, Whole-grain intake of British young people aged 4-18. Br. J. Nutr. vol. 94, pp. 825-831, 2005.

[16] S. Sharma, T. Sheehy, and L. N. Kolonel, Ethnic differences in grains consumption and their contribution to intake of Bvitamins: results of the Multiethnic Cohort Study. Nutr. J. vol. 12, pp. 65, 2013, DOI: 10.1186/1475-2891-12-65.

[17] O. I. Abuzai, Eating Patterns and Physical Activity Characteristics Among Urban and Rural Students in Saudi Arabia. DOCTOR. University of Nebraska -Lincoln, 2012.

[18] Ministry of Agriculture, Saudi Arabian food balance sheets for the period (1999-2001) to (2002-2004) Agricultural Research and Development Affairs, Dept. of Studies Planning and Statistics, (2006). 6th Edition. www.moa.gov.sa/.

[19] N. M. Al Qauhiz, Obesity among Saudi Female University Students: Dietary Habits and Health Behaviors. Egypt Public Health Assoc. vol. 85, pp. 45-59, 2010.

[20] A. F. Hassan, and M. Hussein, Saudi Arabia Grain and feed Annual 2015. USDA. Global Agricultural information network. GAIN Report Number: SA1502, 2015.

[21] The HEALTH GRAIN project (Exploiting Bioactivity of European Cereal Grains for Improved Nutrition and Health Benefits), funded by the European Community Sixth Framework Program, 2005-2010 FOOD-CT-2005-514008. 